Check for updates

Cite this: RSC Adv., 2017, 7, 23846

\section{Plasmonic $\mathrm{W}_{18} \mathrm{O}_{49}$-photosensitized $\mathrm{TiO}_{2}$ nanosheets with wide-range solar light harvesting $†$}

\author{
Junfang Li, Wentao Li, Xinshi Li, Yahui Li, Hua Bai, ${ }^{\star}$ MengChen Li \\ and Guangcheng $\mathrm{Xi}$ (D) *
}

\begin{abstract}
The search for photocatalytic materials that can harvest a wide spectrum of solar light, from ultraviolet (UV) to near infrared (NIR) regions remains one of the most challenging missions. Here, by in situ growing plasmonic $\mathrm{W}_{18} \mathrm{O}_{49}$ nanocrystals on $\mathrm{TiO}_{2}$ nanosheets with exposed $\{001\}$ facets, a hybrid photocatalyst with broad spectrum photocatalytic properties has been fabricated, which can harvest UV, visible, and NIR light to decompose organic contaminants. The results present a new concept that plasmonic transition-metal oxides with a high concentration of oxygen vacancies can be used as non-noble metal photosensitizers to design efficient photocatalysts with high activity.
\end{abstract}

Received 23rd March 2017

Accepted 25th April 2017

DOI: $10.1039 / \mathrm{c} 7 \mathrm{ra03389c}$

rsc.li/rsc-advances to bear self-degradation. ${ }^{24}$ On the other hand, the rapid development of localized surface plasmon resonance (LSPR) photosensitization has also offered a effective means to overcome the limited efficiency of photocatalysts. ${ }^{25}$ That is, semiconductors loaded with noble metal nanoparticles (such as $\mathrm{Au}$ and $\mathrm{Ag}$ ), exhibit high absorption coefficients in a broad UV-visible-NIR spectral range due to their strong LSPR. As a result, plasmonic noble metal nanoparticles may serve as an alternative class of sensitizers in the visible region and the resulting composite catalysts can maintain stability as well. ${ }^{\mathbf{2 6 - 3 0}}$ However, the prohibitive cost and scarcity of the noble metals pose tremendous limitations to widespread use. Therefore, finding robust and efficient alternative sensitizers that are geologically abundant and chemically stable is crucial.

Recently, O-vacancies $\left(\mathrm{V}_{\mathrm{o}}\right)$ in oxide semiconductors have been reported to increase solar light harvesting through narrowing the band gap and also serve as the active sites to improve carrier separation efficiency. ${ }^{31,32}$ An elegant example is the disorder engineered $\mathrm{TiO}_{2}$ nanocrystals, i.e., hydrogenated $\mathrm{TiO}_{2}$ nanocrystals, which exhibit remarkable activity in both photooxidation and photoreduction reactions. ${ }^{4,33}$ More interestingly, it has been revealed that some $\mathrm{V}_{\mathrm{o}}$-rich transition-metal oxides display remarkable LSPR due to their outer d electrons, such as $\mathrm{MoO}_{3-x}$ (ref. 34 and 35) and $\mathrm{TiO}_{2-x}$ (ref. 36) nanocrystals. $\mathrm{WO}_{2.83}$ nanorods ${ }^{37}$ and $\mathrm{W}_{18} \mathrm{O}_{49}$ nanowires ${ }^{38}$ with tunable LSPR have also been successfully prepared. However, the plasmonic transition-metal oxide nanocrystals as sensitizers has not been studied.

Semiconductor hybrid nanostructures with a alternate permutation of band edges at the heterointerface can improve spatial charge separation of photogenerated carriers (electrons and holes) in different parts of the hybrid structures, which can greatly increase the photocatalytic activity. ${ }^{39}$ Among all the hybrid nanostructured photocatalysts, 2D sheet-like materials
Institute of Industrial and Consumer Product Safety, Chinese Academy of Inspection and Quarantine (CAIQ), No. 11, Ronghua South Road, Beijing 100176, P. R. China. E-mail: baih@caiq.gov.cn; xiguangcheng@caiq.gov.cn

$\dagger$ Electronic supplementary information (ESI) available: Experimental procedure, computation details, band structures of $\mathrm{WO}_{3}$ and $\mathrm{W}_{18} \mathrm{O}_{49}$, Raman spectrum and $\mathrm{N}_{2}$ adsorption/desorption isotherms of the anatase phase $\mathrm{TiO}_{2}$ nanosheet, XRD patterns of the samples of $\mathrm{TiO}_{2} / \mathrm{W}_{18} \mathrm{O}_{49}-0.5$ and $\mathrm{TiO}_{2} / \mathrm{W}_{18} \mathrm{O}_{49}-1$. See DOI: $10.1039 / \mathrm{c} 7 \mathrm{ra03389c}$ 
have received much attention because of their very small thickness, high specific surface area, and enhanced light harvesting. ${ }^{40}$ Moreover, due to the gradient in the potentials of different facets, the photogenerated electrons and holes are driven to the different facets and a $\mathrm{p}-\mathrm{n}$ junction can be formed at the nanosheet junctions, which accordingly greatly promote the charge-carriers separation and decreased chance of recombination of electron-hole pairs by the synergetic effect. ${ }^{41}$

Inspired by the pioneer work, herein, we report a facile route for the preparation of $\mathrm{TiO}_{2} / \mathrm{W}_{18} \mathrm{O}_{49}$ hybrid nanosheets. Widerange light harvesting from UV to NIR has been achieved by introducing the in expensive $\mathrm{W}_{18} \mathrm{O}_{49}$ nanocrystals as a new photosensitizer. The $\mathrm{W}_{18} \mathrm{O}_{49}$ nanocoating remarkably improves the photocatalytic efficiency of the $\mathrm{TiO}_{2}$ photocatalyst for the degradation of rhodamine $\mathrm{B}(\mathrm{RhB})$ under full-spectrum, UV, visible, and NIR light irradiation. Their strong responses toward full-spectrum, UV, visible, and NIR are ascribed to a comprehensive benefits of $2 \mathrm{D}$ heterogeneous structure, the exposed surface oxygen vacancies, and the strong LSPR of $\mathrm{W}_{18} \mathrm{O}_{49}$ components.

$\mathrm{TiO}_{2} / \mathrm{W}_{18} \mathrm{O}_{49}$ hybrid nanosheets were prepared from tetrabutyl titanate and tungsten chloride via a two-step solvothermal procedure, consisting the fabrication of (001) crystal faces exposed $\mathrm{TiO}_{2}$ nanosheets and then the introduction of $\mathrm{W}_{18} \mathrm{O}_{49}$ nanocrystals, as illustrated in Fig. 1a. Firstly, the precursor $\mathrm{TiO}_{2}$ nanosheets were solvothermally prepared from tetrabutyl titanate, isopropanol (IPA), and hydrofluoric acid (see the ESI $\dagger$ ). The crystallographic structure and phase purity of the as-

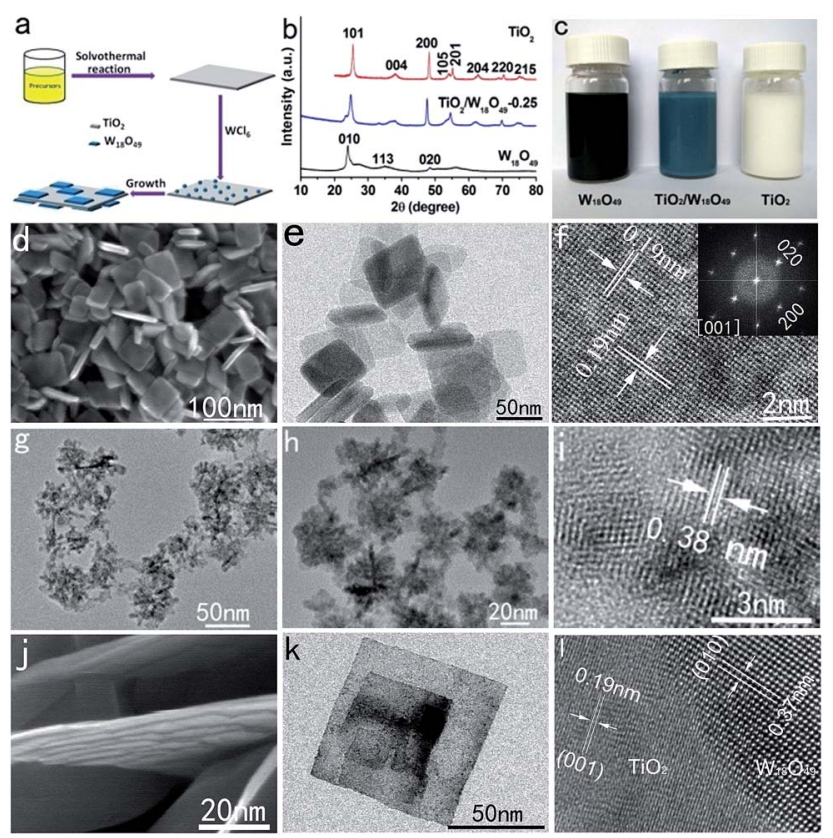

Fig. 1 (a) Schematic illustration of the $\mathrm{TiO}_{2} / \mathrm{W}_{18} \mathrm{O}_{49}$ hybrid nanosheets. ( $b$ and $c$ ) The XRD patterns and corresponding photos of the $\mathrm{TiO}_{2}$ nanosheets, $\mathrm{W}_{18} \mathrm{O}_{49}$ nanocrystals, and $\mathrm{TiO}_{2} / \mathrm{W}_{18} \mathrm{O}_{49}-0.25$ hybrid nanosheets. (d-f) SEM, TEM, and HRTEM images of the $\mathrm{TiO}_{2}$ nanoshees. ( $g-i)$ TEM and HRTEM images of the $\mathrm{W}_{18} \mathrm{O}_{49}$ nanocrystals. (j-l) SEM, TEM, and HRTEM images of the $\mathrm{TiO}_{2} / \mathrm{W}_{18} \mathrm{O}_{49}-0.25$ hybrid nanosheets. obtained sample are first examined by powder X-ray diffraction (XRD) analysis (Fig. 1b). All the diffraction peaks can be indexed as the anatase phase of $\mathrm{TiO}_{2}\left(\mathrm{IL}_{1} / \mathrm{amd}\right)$ with lattice parameters of $a=3.785$ and $c=9.514 \AA$ (JCPDS no. 21-1272). Compared with that relative peak width of standard pattern, the apparently broadened (004) diffraction peak suggests that the as-synthesized product has a very small size along the [001] direction, while the sharp (200) diffraction peak suggests a large crystal size along the $[100] /[010]$ directions. This result suggests that the as-synthesized sample possesses a sheet-like nanostructure. The micro-Raman spectrum (Fig. S1†) taken on the surfaces of the $\mathrm{TiO}_{2}$ sample also shows the typical six Raman modes of anatase phase $\mathrm{TiO}_{2}$. The morphology and structure of the as-synthesized phase-pure $\mathrm{TiO}_{2}$ are characterized by scanning electron microscopy (SEM) and transmission electron microscopy (TEM), as shown in Fig. 1d-e. A panoramic SEM image shows that the $\mathrm{TiO}_{2}$ precursor consists of uniform sheetlike structures with width of $c a$. 50-80 nm (Fig. 1d). These nanosheets possess smooth surface on the top, bottom, and lateral side. TEM image (Fig. 1e) further confirms the welldefined sheet-like construction of these $\mathrm{TiO}_{2}$ particles. From the side view of the nanosheets, the thickness is estimated to be ca. $6 \mathrm{~nm}$ for the nanosheets. Fig. If shows a high-resolution (HR) TEM image of the nanosheets. The fringe spacing of $0.19 \mathrm{~nm}$ agrees well with the spacing of the (200) and (020) lattice planes of anatase $\mathrm{TiO}_{2}$. The diffraction spots of the corresponding FFT pattern (indexed as the [001] zone) can be indexed as the 200 and 020 reflections (inset in Fig. 1f), demonstrating that the rectangular facets are characterized by (001) facets, in agreement with the HRTEM image. Combining the HRTEM images with the FFT and XRD pattern, it is clear that well-defined (001) facet exposed anatase $\mathrm{TiO}_{2}$ nanosheets have been prepared. The $\mathrm{TiO}_{2}$ sample exhibits large BrunauerEmmett-Teller (BET) specific surface areas of $121 \mathrm{~m}^{2} \mathrm{~g}^{-1}$ (Fig. S2 $\dagger$ ).

$\mathrm{W}_{18} \mathrm{O}_{49}$ nanocrystals have been synthesized by directly $\mathrm{WCl}_{6}$ hydrolysis in IPA (see ESI $\dagger$ ). XRD pattern (Fig. 1b) demonstrated that the navy-blue product (Fig. 1c) can be indexed to the monoclinic $\mathrm{W}_{18} \mathrm{O}_{49}$ with lattice parameters of $a=18.318, b=$ 3.782, and $c=14.028 \AA$ (JCPDS no. 05-0392). TEM image show that the as-prepared $\mathrm{W}_{18} \mathrm{O}_{49}$ product is composed of many flower-like nanostructures (Fig. 1g). Higher-magnification TEM images (Fig. 1h) clearly reveal that the nanoflowers are composed of a lot of aggregated nanoparticles. The diameter of the nanoparticles is about 2-3 $\mathrm{nm}$. The HRTEM image demonstrate that the small $\mathrm{W}_{18} \mathrm{O}_{49}$ nanoparticles are highly crystalline (Fig. 1i).

The hybrid $\mathrm{TiO}_{2} / \mathrm{W}_{18} \mathrm{O}_{49}$ nanosheets are prepared by a facile tungsten chloride $\left(\mathrm{WCl}_{6}\right)$ hydrolysis procedure under solvothermal conditions using the $\mathrm{TiO}_{2}$ nanosheets as the template. A series of samples were synthesized by adding different amounts of $\mathrm{WCl}_{6}$. Specifically, 0.25, 0.5, and $1.0 \mathrm{~g}$ of $\mathrm{WCl}_{6}$ were used, and the samples were named as $\mathrm{TiO}_{2} / \mathrm{W}_{18} \mathrm{O}_{49^{-}}$ 0.25 , $\mathrm{TiO}_{2} / \mathrm{W}_{18} \mathrm{O}_{49}-0.5$, and $\mathrm{TiO}_{2} / \mathrm{W}_{18} \mathrm{O}_{49}-1.0$, respectively. As a representative sample of the hybrid materials, the crystallographic structure and morphology of the sample $\mathrm{TiO}_{2} / \mathrm{W}_{18} \mathrm{O}_{49^{-}}$ 0.25 was characterized by XRD, SEM, TEM, and HRTEM. 
Visually, the pristine $\mathrm{TiO}_{2}$ nanosheets appear as milky, which turn blue with the introduction of $\mathrm{W}_{18} \mathrm{O}_{49}$ nanocoating (Fig. 1c). The successful formation of $\mathrm{TiO}_{2} / \mathrm{W}_{18} \mathrm{O}_{49}$ hybrid structures is confirmed by XRD analysis. Typical XRD pattern recorded from the sample of $\mathrm{TiO}_{2} / \mathrm{W}_{18} \mathrm{O}_{49}-0.25$ are shown in Fig. $1 \mathrm{~b}$. All of the diffraction peaks can be indexed to the anatase $\mathrm{TiO}_{2}$ (JCPDS no. 21-1272) and monoclinic $\mathrm{W}_{18} \mathrm{O}_{49}$ (JCPDS no. 05-0392). With the increase of $\mathrm{WCl}_{6}$ concentration, the diffraction intensity of the $\mathrm{W}_{18} \mathrm{O}_{49}$ phase becomes stronger (Fig. S3 $\dagger$ ), indicating the increasing content of $\mathrm{W}_{18} \mathrm{O}_{49}$ in the formed $\mathrm{TiO}_{2} / \mathrm{W}_{18} \mathrm{O}_{49}$ hybrid structure. The morphology of the as-prepared sample $\mathrm{TiO}_{2} /$ $\mathrm{W}_{18} \mathrm{O}_{49}-0.25$ was first characterized by SEM. As shown in Fig. $1 \mathrm{j}$, the introduction of $\mathrm{W}_{18} \mathrm{O}_{49}$ does not bring about significant changes in the nanosheet morphology. However, the surface of the sheets becomes very rough. Fig. 1k shows the TEM image of the hybrid nanosheets. Compared with the morphology of pure $\mathrm{TiO}_{2}$ nanosheets, the surface of the $\mathrm{TiO}_{2} / \mathrm{W}_{18} \mathrm{O}_{49} 9^{-0.25}$ nanosheets is coated with a thin layer of $\mathrm{W}_{18} \mathrm{O}_{49}$ nanosheets or nanodots (Fig. 1k). From the HRTEM image of the hybrid nanosheets (Fig. 11), there are two types of crystal structures in the hybrid nanosheets. The crystal lattice in part 1 shows an interplanar spacing of $0.19 \mathrm{~nm}$, which corresponds to the (200) and (020) lattice planes of $\mathrm{TiO}_{2}$. The crystal lattice in part 2 reveals that a particle with a size of about $7 \mathrm{~nm}$ is a single crystal with an interplanar spacing of $0.37 \mathrm{~nm}$, which corresponds to the (010) crystalline plane of $\mathrm{W}_{18} \mathrm{O}_{49}$. Such an observation strongly suggests that $\mathrm{W}_{18} \mathrm{O}_{49}$ nanoparticles are embedded in the $\mathrm{TiO}_{2}$ nanosheets after the solvothermal reaction. The chemical composition of the sample was confirmed by EDS analysis (Fig. S4 $\dagger$ ), which showed strong $\mathrm{Ti}, \mathrm{W}$, and $\mathrm{O}$ signals. With increasing amount of $\mathrm{WCl}_{6}$ to $0.5 \mathrm{~g}$, more $\mathrm{W}_{18} \mathrm{O}_{49}$ nanosheets can be clearly observed on the $\mathrm{TiO}_{2}$ nanosheets (Fig. S5a†). When the amount of $\mathrm{WCl}_{6}$ was increased to $1 \mathrm{~g}$, a more complex sheet-like hierarchical structure was formed (Fig. S5b†). On the basis of the above results, obviously, the $\mathrm{TiO}_{2}$ nanosheet precursor plays an important template role in the growth of the hybrid 2D nanosheets.

The photocatalytic activity of the $\mathrm{TiO}_{2} / \mathrm{W}_{18} \mathrm{O}_{49}$ hybrid nanosheets was evaluated for the degradation of RhB under fullspectrum, visible, and NIR light irradiation. Fig. 2a presents the full-spectrum-light photocatalytic degradation of RhB in the presence of different photocatalysts. Compared with pure $\mathrm{TiO}_{2}$ nanosheets and $\mathrm{W}_{18} \mathrm{O}_{49}$ nanoparticles, the hybrid $\mathrm{TiO}_{2} / \mathrm{W}_{18} \mathrm{O}_{49}$ nanosheet samples exhibit greatly enhanced photocatalytic efficiency. Among them, the sample of $\mathrm{TiO}_{2} / \mathrm{W}_{18} \mathrm{O}_{49}-0.25$ displays the highest photocatalytic activity. After irradiation for $50 \mathrm{~min}$, the degradation fractions for different photocatalysts are $21.6 \%\left(\mathrm{TiO}_{2}\right.$ nanosheets), $43.8 \%\left(\mathrm{~W}_{18} \mathrm{O}_{49}\right)$, and $95.2 \%\left(\mathrm{TiO}_{2} /\right.$ $\left.\mathrm{W}_{18} \mathrm{O}_{49}-0.25\right)$. Under visible light irradiation $(\lambda>450 \mathrm{~nm})$, the $\mathrm{TiO}_{2} / \mathrm{W}_{18} \mathrm{O}_{49}-0.25$ hybrid nanosheets also show the highest photocatalytic activity, followed by $\mathrm{W}_{18} \mathrm{O}_{49}$ nanoparticles, $\mathrm{TiO}_{2}$ nanosheets. As shown in Fig. 2b, after irradiation for $4 \mathrm{~h}$, the degradation fractions for different photocatalysts are $18.5 \%$ ( $\mathrm{TiO}_{2}$ nanosheets), $65.7 \%\left(\mathrm{~W}_{18} \mathrm{O}_{49}\right.$ nanoparticles), and $97.5 \%$ $\left(\mathrm{TiO}_{2} / \mathrm{W}_{18} \mathrm{O}_{49}-0.25\right)$. Considering that visible light itself could not induce $\mathrm{TiO}_{2}$ photoexcitation, the small quantity of degradation of $\mathrm{RhB}$ in the $\mathrm{TiO}_{2}$ nanosheets should be attributed to
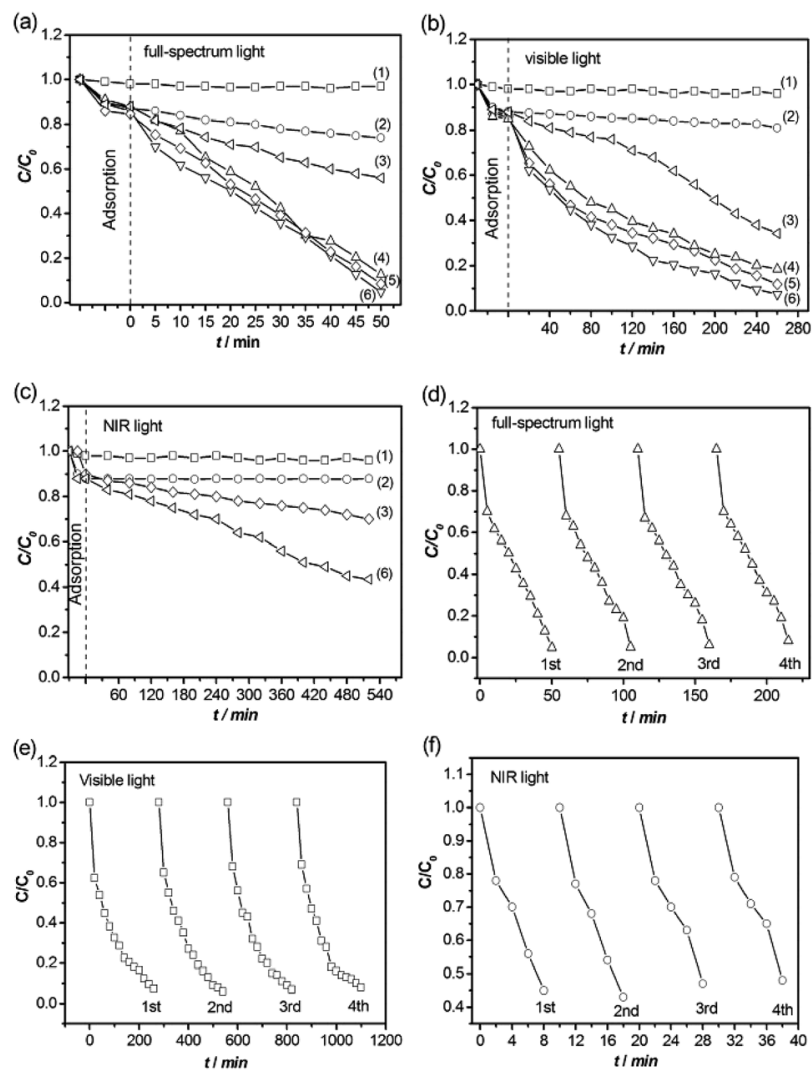

Fig. 2 Photodegradation of RhB in the presence of different photocatalysts under (a) full-spectrum light, (b) visible light, and (c) NIR light irradiation. Blank included for comparison (1), $\mathrm{TiO}_{2}$ nanosheets (2), $\mathrm{W}_{18} \mathrm{O}_{49}$ nanocrystals (3), $\mathrm{TiO}_{2} / \mathrm{W}_{18} \mathrm{O}_{49}-1.0$ (4), $\mathrm{TiO}_{2} / \mathrm{W}_{18} \mathrm{O}_{49}-0.5$ (5), and $\mathrm{TiO}_{2} / \mathrm{W}_{18} \mathrm{O}_{49}-0.25$ (6). (d) Initial decomposition rates vs. $\mathrm{W}_{18} \mathrm{O}_{49}$ loading concentration. Four cycles of the photocatalytic degradation of $\mathrm{RhB}$ using sample of $\mathrm{TiO}_{2} / \mathrm{W}_{18} \mathrm{O}_{49}-0.25$ as photocatalyst under (d) full-spectrum light, (e) visible light, and (f) NIR light irradiation.

the adsorption and sensitization effect of the dye molecules. Moreover, $\mathrm{TiO}_{2} / \mathrm{W}_{18} \mathrm{O}_{49}$ hybrid nanosheets also show noticeable photocatalytic activity under NIR light illumination, in great contrast to pristine $\mathrm{TiO}_{2}$ nanosheets (Fig. 2c). After irradiation for $8 \mathrm{~h}$, the degradation fractions for different photocatalysts are $12.1 \%$ ( $\mathrm{TiO}_{2}$ nanosheets), $23.7 \%\left(\mathrm{~W}_{18} \mathrm{O}_{49}\right.$ nanoparticles), and $56.8 \%\left(\mathrm{TiO}_{2} / \mathrm{W}_{18} \mathrm{O}_{49}-0.25\right)$. It is should be mentioned that the reduced concentration when use pure $\mathrm{TiO}_{2}$ nanosheets as catalysts should be attributed to the adsorption of the nanosheets. In addition to efficiency, stability and recyclability of photocatalysts are also important features for applications. After the RhB molecules are completely decomposed, centrifugation of the solution enables the $\mathrm{TiO}_{2} / \mathrm{W}_{18} \mathrm{O}_{49}-0.25$ nanosheets to be easily collected to catalyze a new reaction. Fig. $2 \mathrm{~d}-\mathrm{f}$ plots the kinetic curves for degradation of RhB solution under fullspectrum light, visible light, and NIR light irradiation. The $\mathrm{TiO}_{2} / \mathrm{W}_{18} \mathrm{O}_{49}-0.25$ nanosheet photocatalyst can be effectively recycled at least four times without an apparent decrease in photocatalytic activity, which demonstrates their high stability.

The above results reveal that the $\mathrm{W}_{18} \mathrm{O}_{49}$ loading on the $\mathrm{TiO}_{2}$ nanosheets remarkably improves the photocatalytic efficiency. 
These enhanced photocatalytic activity might be caused by the following structural features. Firstly, the observed improved photocatalytic activity under visible and NIR light illumination should come from LSPR induced by the abundant oxygen vacancies contained in the $\mathrm{W}_{18} \mathrm{O}_{49}$ nanocrystals. UV/Vis/NIR absorption spectroscopy was employed to characterize the absorption properties of the $\mathrm{TiO}_{2}$ nanosheets, $\mathrm{W}_{18} \mathrm{O}_{49}$ nanocrystals, and $\mathrm{TiO}_{2} / \mathrm{W}_{18} \mathrm{O}_{49}$ hybrid nanosheets. The UV/Vis/NIR results acquired from the samples are presented in Fig. 3a. All of the spectra exhibit the almost same absorption band from the shorter wavelength side to around 370-385 nm, which corresponds to the band-gap absorption of $\mathrm{TiO}_{2}$ and $\mathrm{W}_{18} \mathrm{O}_{49}$. Distinct absorption behaviors occur at the sub-band gap absorption range. Compared with the pristine $\mathrm{TiO}_{2}$ nanosheets, the pure $\mathrm{W}_{18} \mathrm{O}_{49}$ nanocrystals displays a very strong LSPR from visible to NIR regions. As a results, the hybrid $\mathrm{TiO}_{2} / \mathrm{W}_{18} \mathrm{O}_{49}$ correspondingly show greatly enhanced visible and NIR absorption compared with pristine $\mathrm{TiO}_{2}$ nanosheets.

Studies on the electronic properties of the blue tungsten oxide have revealed that $\mathrm{WO}_{3-\mathrm{x}}$ undergoes a transition from insulator to metal at $x=0.1$, as the localized polaronic wave functions begin to overlap and form delocalized states. ${ }^{42}$ As a result, for $x>0.1$ in $\mathrm{WO}_{3-\mathrm{x}}$, the electrical and optical properties are dominated by free electrons, that is to a half-metallicity. ${ }^{43}$ Our theoretical calculation suggests that the introduction of the oxygen vacancy endows the $\mathrm{W}_{18} \mathrm{O}_{49}$ with metal-like property (calculation process see ESI $\dagger$ ). Fig. S6 $\dagger$ exhibits the electronic structures of monoclinic phase $\mathrm{WO}_{3}$ and $\mathrm{W}_{18} \mathrm{O}_{49}$. Compared with the $\mathrm{WO}_{3}$, the band gap of $\mathrm{W}_{18} \mathrm{O}_{49}$ is clearly reduced and meanwhile the Femi level ( 0 eV level) inserts into energy band, indicating that the $\mathrm{W}_{18} \mathrm{O}_{49}$ exhibits a metallike character. The calculation results demonstrate that large quantity of free electrons exist in the $\mathrm{W}_{18} \mathrm{O}_{49}$, suggesting that it has a stronger ability to absorb light. Therefore, the $\mathrm{W}_{18} \mathrm{O}_{49}$ nanocrystals can be considered as a plasmonic photosensitizer, similar to the case of $\mathrm{Au}$ and $\mathrm{Ag}$ nanoparticles, charge transfer from photoexcited plasmonic $\mathrm{W}_{18} \mathrm{O}_{49}$ nanocrystals to the $\mathrm{TiO}_{2}$ nanosheets under visible and NIR irradiation.

Secondly, the LSPR of samples may enhance the local electric field of tungsten oxide and titanium dioxide and accordingly promote the charge-carrier separation. As a evidence, an obvious reduction of the photoluminescence of the $\mathrm{TiO}_{2} /$
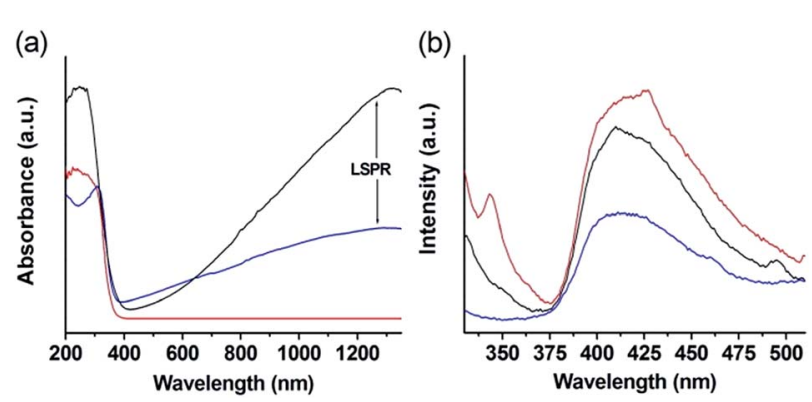

Fig. 3 UV-Vis-NIR adsorption spectra (a) and PL spectra (b) of the samples. Blue line: $\mathrm{TiO}_{2} / \mathrm{W}_{18} \mathrm{O}_{49}-0.25$ hybrid nanosheets; black line: $\mathrm{W}_{18} \mathrm{O}_{49}$ nanocrystals; red line: $\mathrm{TiO}_{2}$ nanosheets.
$\mathrm{W}_{18} \mathrm{O}_{49}$ hybrid nanosheets can observed as compared with that of $\mathrm{TiO}_{2}$ nanosheets or $\mathrm{W}_{18} \mathrm{O}_{49}$ nanocrystals alone, indicating that the coupling of $\mathrm{TiO}_{2}$ and $\mathrm{W}_{18} \mathrm{O}_{49}$ in the hybrid nanostructure effectively diminish the recombination of photoinduced electron-hole pairs, which is beneficial to the photocatalytic performance (Fig. 3b).

At the same time, the photoelectrochemical properties of the $\mathrm{TiO}_{2} / \mathrm{W}_{18} \mathrm{O}_{49}$ hybrid nanosheets are examined by means of photocurrent responses. We measured the photocurrent response in a three-electrode electrochemical cell with $\mathrm{Ag} / \mathrm{AgCl}$ as the reference electrode and Pt wire as the counter electrode (see ESI $\dagger$ ). The photocurrent responses for all samples under dark are very low, while obvious current responses could be discerned from 0.1 to $1.0 \mathrm{eV}$ (vs. $\mathrm{Ag} / \mathrm{AgCl}$ ) under full-spectrum light (Fig. S7 $\dagger$ ). The $\mathrm{TiO}_{2} / \mathrm{W}_{18} \mathrm{O}_{49}$ hybrid nanosheets show the higher photocurrent density compared with the pure $\mathrm{TiO}_{2}$ nanosheets and $\mathrm{W}_{18} \mathrm{O}_{49}$ nanocrystals, indicating that $\mathrm{TiO}_{2} /$ $\mathrm{W}_{18} \mathrm{O}_{49}$ hybrid nanosheets have better carrier separation efficiency due to the heterojunction effect. In addition, the direct growth of $\mathrm{W}_{18} \mathrm{O}_{49}$ nanocrystals on the $\mathrm{TiO}_{2}$ nanosheets could ensure good mechanical adhesion, and more importantly good electrical contact with the active (001) facets of $\mathrm{TiO}_{2}$ that also serves as the reactive sites.

\section{Conclusions}

In summary, we have synthesized novel hybrid $\mathrm{TiO}_{2} / \mathrm{W}_{18} \mathrm{O}_{49}$ nanosheets by a facile solvothermal method. Importantly, the hybrid nanosheets show strong and wide range of light absorption from UV to NIR. As expected, the as-prepared hybrid $\mathrm{TiO}_{2} / \mathrm{W}_{18} \mathrm{O}_{49}$ nanosheets exhibit superior photocurrent response and photocatalytic activity for degradation of RhB under full-spectrum, visible, and NIR irradiation. This work will likely inspire further exploration for non-precious metal photosensitizing hybrid nanostructures with high potential for photocatalytic and optaelectronic applications.

\section{Acknowledgements}

This work received financial support from the Dean Fund of Chinese Academy of Inspection and Quarantine (2016JK025) and the National Natural Science Foundation of China (51472226).

\section{References}

1 A. Fujishima and K. Honda, Nature, 1972, 238, 37-38.

2 Z. G. Zou, J. H. Ye, K. Sayama and H. Arakawa, Nature, 2001, 414, 625-627.

3 D. L. Lu, T. Takata, N. Saito, Y. Inoue and K. Domen, Nature, 2006, 440, 295.

4 X. B. Chen, L. Liu, P. Y. Yu and S. S. Mao, Science, 2011, 331, 746-750.

5 J. Liu, Y. Liu, N. Y. Liu, Y. Z. Han, X. Zhang, H. Huang, Y. Lifshitz, S. T. Lee, J. Zhong and Z. H. Kang, Science, 2015, 347, 970-974. 
6 Z. G. Yi, J. H. Ye, N. Kikugawa, T. Kako, S. X. Ouyang, H. S. Williams, H. Yang, J. J. Y. Cao, W. J. Luo, Z. S. Li, Y. Liu and R. L. Withers, Nat. Mater., 2010, 9, 559-564.

7 A. Kuto and Y. Miseki, Chem. Soc. Rev., 2009, 38, 253-278.

8 X. C. Wang, K. Maeda, A. Thomas, K. Takanabe, G. Xin, J. M. Carlsson, K. Domen and M. Antonietti, Nat. Mater., 2009, 8, 76.

9 S. S. K. Ma, K. Maeda, R. Abe and K. Domen, Energy Environ. Sci., 2012, 5, 8390.

10 J. Tian, Y. H. Sang, G. W. Yu, H. D. Jiang, X. N. Mu and H. Liu, Adv. Mater., 2013, 25, 5075.

11 Y. H. Sang, Z. H. Zhao, M. W. Zhao, P. Hao, Y. H. Leng and H. Liu, Adv. Mater., 2015, 27, 363.

12 G. Wang, B. B. Huang, X. C. Ma, Z. Y Wang, X. Y. Qin, X. Y. Zhang, Y. Dai and M. Whangbo, Angew. Chem., Int. Ed., 2013, 52, 4810.

13 Q. J. Xiang, J. G. Yu and M. Jaroniec, J. Am. Chem. Soc., 2012, 134, 6575.

14 H. G. Yang, C. H. Sun, S. Z. Qiao, J. Zou, G. Liu, S. C. Smith, H. M. Cheng and G. Q. Lu, Nature, 2008, 453, 638.

15 X. B. Chen and S. S. Mao, Chem. Rev., 2007, 107, 289.

16 Y. Ma, X. Wang, Y. Jia, X. Chen, H. Han and C. Li, Chem. Rev., 2014, 114, 9987.

17 R. Asahi, T. Morikawa, T. Ohwaki, K. Aoki and Y. Taga, Science, 2001, 293, 269.

18 S. U. M. Khan, M. Al-Shahry and W. B. Ingler, Science, 2002, 297, 2243.

19 S. Sakthivel and H. Kisch, Angew. Chem., Int. Ed., 2003, 42, 4908.

20 S. W. Liu, J. G. Yu and M. Jaroniec, J. Am. Chem. Soc., 2010, 132, 11914.

21 C. Han, N. Zhang and Y. J. Xu, Nano Today, 2016, 11, 351372.

22 L. Yuan, M. Q. Yang and Y. J. Xu, Nanoscale, 2014, 6, 63356345.

23 E. Bae, W. Choi, J. Park, H. S. Shin, S. B. Kim and J. S. Lee, J. Phys. Chem. B, 2004, 108, 14093.

24 X. B. Chen, S. H. Shen, L. J. Guo and S. S. Mao, Chem. Rev., 2010, 110, 6503.
25 P. Wang, B. B. Huang, X. Y. Qin, X. Y. Zhang, Y. Dai, J. Y. Wei and M. H. Whangbo, Angew. Chem., Int. Ed., 2008, 47, 7931.

26 A. Marimuthu, J. W. Zhang and S. Linic, Science, 2013, 339, 1590.

27 Z. F. Bian, T. Tachikawa, P. Zhang, M. Fujitsuka and T. Majima, J. Am. Chem. Soc., 2014, 136, 458.

28 R. B. Jiang, B. X. Li, C. H. Fang and J. F. Wang, Adv. Mater., 2014, 26, 5274.

29 B. Weng, Q. Quan and Y. J. Xu, J. Mater. Chem. A, 2016, 4, 18366-18377.

30 N. Zhang, C. Han, Y. J. Xu, J. J. Foley IV, D. T. Zhang, J. Codrington, S. K. Gray and Y. G. Sun, Nat. Photonics, 2016, 10, 473-482.

31 F. C. Lei, Y. F. Sun, K. Liu, S. Gao, L. Liang, B. C. Pan and Y. Xie, J. Am. Chem. Soc., 2014, 136, 6826.

32 J. Q. Yan, T. Wang, G. J. Wu, W. L. Dai, N. J. Guan, L. D. Li and J. L. Gong, Adv. Mater., 2015, 27, 1580.

33 X. B. Chen, L. Liu and F. Q. Huang, Chem. Soc. Rev., 2015, 44, 1861.

34 Q. Q. Huang, S. Hu, J. Zhuang and X. Wang, Chem.-Eur. J., 2012, 18, 15283.

35 H. F. Cheng, T. Kamegawa, K. Mori and H. Yamashita, Angew. Chem., Int. Ed., 2014, 53, 2910.

36 T. R. Gordon, M. Cargnello, T. Paik, F. Mangolini, R. T. Weber, P. Fornasiero and C. B. Murray, J. Am. Chem. Soc., 2012, 134, 6751.

37 K. Manthiram and A. P. Alivisatos, J. Am. Chem. Soc., 2012, 134, 3995.

38 G. C. Xi, S. X. Ouyang, P. Li, J. H. Ye, Q. Ma, N. Su, H. Bai and C. Wang, Angew. Chem., Int. Ed., 2012, 51, 2395.

39 X. H. Gao, H. B. Wu, L. X. Zhang, Y. J. Zhong, Y. Hu and X. W. Lou, Angew. Chem., Int. Ed., 2014, 126, 6027.

40 J. X. Zhu, K. Sakaushi, G. Clavel, M. Shalom, M. Antonietti and T. P. Fellinger, J. Am. Chem. Soc., 2015, 137, 5480.

41 X. Y. Chen, Y. Zhou, Q. Liu, Z. D. Li, J. G. Liu and Z. G. Zou, ACS Appl. Mater. Interfaces, 2012, 4, 1813.

42 E. Salje and B. Guttler, Philos. Mag. B, 1984, 50, 607.

43 H. Bai, W. C. Yi, J. Y. Liu, Q. Lv, Q. Zhang, Q. Ma, H. F. Yang and G. C. Xi, Nanoscale, 2016, 8, 13545. 